\title{
Medical students' reflections on the meaning of disease and illness in South African communities
}

\author{
F C J Stevens, ${ }^{1} \mathrm{PhD} ; \mathbf{S}$ Naidoo, ${ }^{2} \mathrm{MD}, \mathrm{PhD} ; \mathbf{M}$ Taylor, ${ }^{2} \mathrm{PhD} ; \mathbf{S}$ Knight,${ }^{2} \mathrm{MD}$ \\ ${ }^{1}$ Department of Educational Development and Research, Faculty of Health, Medicine and Life Sciences, Maastricht University, The Netherlands \\ ${ }^{2}$ Department of Public Health Medicine, College of Health Sciences, University of KwaZulu-Natal, Durban, South Africa
}

Corresponding author: F C J Stevens (fred.stevens@maastrichtuniversity.nl)

\begin{abstract}
Background. Many healthcare education programmes embody methods of 'active learning' in authentic contexts. What students learn from authentic early experiences when exposed to healthcare in local communities is less clear.

Objectives. We explored medical students' learning in South African communities by analysing their reflection on and meaning given to interactions with patients.

Methods. A directed content analysis was done on a sample of 58 students' reflection reports with regard to the meaning of disease. Four different perspectives were coded, and labelled as positivist, compassionate, moralist and spiritualist.

Results. Students documented their greater understanding of their patients' circumstances and their compassion and respect for patients and their diseases. Overall, the positivist biomedical perspective was observed, followed by the compassionate perspective. In their reflections, students expressed combined perspectives, i.e. the positivist perspective together with one or more of the others. Moralist and spiritualist perspectives were also observed in the data. The students indicated the benefits they had experienced, i.e. by visiting a patient in his/her home environment, they were able to construct and contextualise the patients' lives more holistically.

Conclusions. Raising medical students' awareness of the realities of seeing patients in primary health clinics, district hospitals and at home, may contribute to their understanding of the meaning of disease and illness and their ability to better serve communities in need.
\end{abstract}

Afr J Health Professions Educ 2019;11(1):6-11. DOI:10.7196/AJHPE.2019.v11i1.1014

This article provides an understanding of the different perspectives of medical students on patients and their health problems during authentic early experiences (AEEs) in local South African (SA) communities. In the medical education literature, AEE refers to medical students having first contact with people in the clinical or social context, enhancing students' learning regarding health, illness or disease, and the role of the health professional. ${ }^{[1,2]}$ It includes making meaning from direct experience that is beneficial to the student through guided reflection and analysis. ${ }^{[3,4]}$ Over the years, AEE has become popular in medical education because of the insight that early experience can have a formative influence, fostering a more socially responsive career choice in later years. ${ }^{[5]}$ Furthermore, it has been suggested that early patient contact increases students' motivation for studying the theoretical background of medicine, and offers opportunities for learning communication skills and how to establish a good doctorpatient relationship. ${ }^{[2,6]}$

Many public health and healthcare education programmes currently embody experiential learning through problem-based learning strategies and methods of 'active learning. The literature also reports on how students learn in authentic contexts through their service learning. ${ }^{[7]}$ What students learn from AEE contexts, such as being exposed to healthcare in local communities, and whether this is what we expect them to learn, is less clear. It is important to know about such learning in the light of current discussions on medical education reforms, where concerns are raised about students' lack of compassion, responsibility and social responsibility and whether they are sufficiently prepared to become responsible professionals. ${ }^{[8-12]}$
Authentic early clinical experience is known to foster more socially responsive attitudes in students. The Selectives Programme at the University of KwaZulu-Natal (UKZN), Durban, SA (data used in this article) comprises the community-orientated primary care (COPC) approach to impart a population perspective to medical students, using public health knowledge and skills. Assignments require that students reflect on health and illness and not only on the patient's disease. In COPC, the student starts with the patient and is guided to consider how social determinants impact on the patient's illness, but also to consider a population perspective on their disease and related 'upstream' factors.

Supported by the analysis of reflections on the meaning of disease and illness, we explored medical students' learning in the community by examining their reflection on and meaning given to their interactions with patients. We studied the perspectives through which undergraduate SA medical students observe, describe and learn about patients, their community and their daily life. Our assumption was that students' observations and descriptions of these patients, their social context and its meaning are related to their 'worldview..$^{[13-15]}$ Worldview, translated from the German Weltanschauung, literally means the perception of the world. In our case, it indicates the perspective from which students typically view health, illness and disease questions, and their responses. ${ }^{[15-18]}$

Our interest in this topic was triggered by the observation that, typically, the biomedical perspective, or positivist worldview, in healthcare is the leading paradigm in how medical curricula are shaped, and therefore also in how students implicitly or explicitly are socialised into the profession of 
medicine. ${ }^{[9,19-22]}$ We were curious whether from the students' descriptions of interactions with the patient, and their deeper understanding of the experiences of the patient, other views could be assessed, enriching the positivist perspective. Our study was guided by the following two research questions:

- What perspectives do undergraduate medical students use in their observations and reports of patients in authentic local contexts?

- What meaning do students give to their observations and patient interviews in authentic local contexts?

\section{Methods}

\section{Study design}

This study used a qualitative, phenomenology-orientated research design by means of content analysis.

\section{Source of the data}

The data source was medical students' reflections on the meaning of disease, data available from undergraduates taking part in the Selectives Programme at the medical school of UKZN ${ }^{[23]}$ The programme was developed a few years ago in accordance with the mission of the university. Academics from the public health discipline at UKZN developed a programme to address national and international education imperatives to ensure that medical students become socially accountable graduates, with a strong population perspective. ${ }^{[23,24]}$ Through years 2,3 and 4 of their medical studies, students participate in primary and public health activities and subsequently are in contact with the local communities where they originate. Based on the COPC approach, students link clinical activities with public health, identify a community-based research question, and undertake a small study that informs a community diagnosis, culminating in a health-promotion intervention. ${ }^{[23]}$

\section{Extraction of the data}

The students' reflections on the meaning of disease were completed as part of an assessed component of the programme. They identified a patient with a chronic disease, who they were required to visit twice annually for 3 years. After describing the patient's disease, their family, and social and environmental circumstances, they reflected on their experience of the patient's illness and how this related to their own understanding of health and disease as a medical practitioner.

\section{Coding and data analysis}

While we acknowledge the social constructivist viewpoint that individuals develop different meanings directed towards objects, persons or things, ${ }^{[13,14,25]}$ we applied a directed qualitative content analysis to the phenomena. ${ }^{[26]}$ The main strength of this approach is that it enabled us to support and/ or extend existing theory, while at the same time protecting us better against the fallacy of naive inductivism. ${ }^{[27]}$ In the most common qualitative data analysis, categories for coding are directly derived from the text. In the directed approach, this is done differently, as the analysis starts from theoretical concepts or categories as guidance for the coding. ${ }^{[2]}$ The reflections were analysed for the students' worldviews, while maintaining independence of those of the researchers. The process that followed ensured that each reflection was read by more than one researcher and after some discussion by the researchers, consensus regarding the students perspectives was obtained.
Informed by an extensive narrative review ${ }^{[28]}$ of the sociological and anthropological literature on doctor-patient interactions, conceptualisations of the sick role, and exploratory reading of the students' reflection documents, we explored four perspectives for our coding. These were originally developed by Philipsen ${ }^{[15]}$ in a study on norms and values in healthcare, and labelled as positivist, compassionate, moralist and spiritualist perspectives. These four perspectives are explained and discussed in more detail in the results section.

The authors of this article, one medical sociologist/educationalist experienced in qualitative methodologies, and three public health experts, were involved in the directed content analysis, and discussed and substantiated the four perspectives and the key features. Each independently first analysed the students' reflections on the meaning of disease in the light of the four perspectives.

Among the challenges in a directed qualitative content analysis are neutrality, confirmability and trustworthiness, in particular as 3 of the 4 researchers were also assessors on the Selectives Programme. ${ }^{[26]}$ To increase trustworthiness, a second round was held in which the 4 reviewers (in pairs) discussed their procedures and findings and compared observations, key quotes and classifications. ${ }^{[28]}$ Then, in a third round, all 4 researchers met to come to the final conclusions and discuss findings and uncertainties in assigning perspectives to quotes. For example, during the analysis, in some cases it proved to be challenging to make the distinction between the student's and the patient's meaning of disease, as will be discussed in more detail below.

The variety and different student perspectives of the reflections provided the basis for this article. The reflections were analysed for the students' worldviews, while maintaining independence of those of the researchers. Each reflection was read by more than one researcher and a consensus position was obtained after some discussion.

\section{Ethical approval}

The Biomedical Research Ethics Committee of UKZN approved the ongoing evaluation and analysis of the undergraduate medical programme (ref. no. UKZN-BREC 201/04).

\section{Participants}

In 2015, 256 medical students participated in the Selectives One Programme Sixty percent of these students were female and just over $60 \%$ came from rural or township disadvantaged areas. Of the student population, $70 \%$ are black African, 22\% Indian, 5\% mixed race and 3\% white. At the time of our investigation, half of these students had completed the Selectives Programme and submitted a document where they reflected on the meaning of disease as one of the requirements of the programme. Our sample $(n=58)$ was taken from these documents. Efforts were made to avoid selection or demographic bias by randomly selecting these 58 cases (using random numbers) from the available documents. The 58 reflections were from students who represented the demographics of the class.

\section{Results}

\section{Perspectives on disease, health and illness}

Four perspectives guided our content analysis of students' reflections on the meaning of disease, labelled as positivist, compassionate, moralist and spiritualist perspectives. We describe these below, substantiating each with literature and quotes from students' documents. 


\section{The positivist perspective}

In the positivist perspective, the world is seen as an objective reality exterior to ourselves. The positivist distinguishes the objective from the subjective social reality, making use of science to produce true knowledge. ${ }^{[28]}$ Only empirical data, evidence, objectivity and rational considerations can shape this true knowledge. It includes how we look at healthcare issues and often also at medical education. Applied to health and healthcare, it means that there is a preference for a biomedical definition of health and illness, as well as a disposition to look for causes and outcomes in the objective reality, outside ourselves. In this view, connotations with and meanings and perceptions of illness play a minor role. The positivist student/physician will possibly be interested in the 'disease', the particular 'case' to be observed and how the case should be diagnosed and treated. A detached concern and 'face-work' (creating a self, presenting to others, i.e. a medical professional presented to the patient) typify the interactions of the health professional with the patient. ${ }^{[29-31]}$ Evidence-based medicine is a typical product of the positivist (or scientific) perspective. One of the students highlighted the patient's concerns about people's perceptions of the disease and the possible side-effects of the treatment:

'The patient was very worried about people's perceptions of his disease. He mentioned that gout and arthritis are often associated with very old people and he was afraid that he would "be old before his time". The patient had not been on chronic medicines before this diagnosis and thus he felt afraid that it would affect his ability to function optimally during the workday because of side-effects such as drowsiness. He did not experience any drowsiness but he did have bouts of diarrhoea. This affected the patient because he would not go to work for the first few days of starting his treatment. Further into his treatment, however, he believed that the arthritis medication might have been causing him to be constipated.'

Another student's reflections were a typical example of detached concern regarding a patient with chronic disease:

'The experience of being a chronic patient takes time to get used to, but does normalise as part of the daily routine. Families are affected by a chronic disease, as time has to be taken off work to attend to the patient. I realised the importance of addressing parents' fears and concerns, as this impacts how the disease affects the child's daily life.

\section{The compassionate perspective}

In the compassionate perspective, the subjective constructivist reality prevails. It means the ill person and his/her narrative of how s/he perceives the illness are of primary importance to the observer. A compassionate practitioner/student is primarily focused on the ill person within his/ her subjective environment. Accepting illness, learning how to live with one's incapacities and sharing subjective experiences with others are observations within this perspective. For the patient, the compassionate perspective means being accepted and having the privilege to receive understanding, empathy and compassion from others. One observation is that the compassionate perspective is an essential undercurrent, vital to the sovereignty of the positivist worldview, where patients are dealt with as cases and projects. Therefore, students described engaging in a logical effort focused on treatment and care of well-defined, circumscribed health problems. ${ }^{[15,31]}$ One student described it as follows:
'My feelings toward my patient grew, and the more I listened and empathised, the more I felt for her and understood her. I felt concern for her and her family, knowing that it would be difficult to cope with her health problem. I felt the need to help them. The way that my patient expressed her feelings to me, directly allowed me to empathise with her and to see things from her perspective.'

Combined with a positivist perspective, a student reported:

'P...'s life has been changed by living with HIV and she saw a need to create new life goals and adjust older ones. She expected it to alter only her daily routine with only having to add some medication during the day, but it did more than that. She was able to identify the good and the not so good adjustments that she would have to make; that's her life now and she has accepted and even embraced this new aspect to it.'

\section{The moralist perspective}

Seen from the perspective of the moralist, illness and disease are caused by carelessness, irresponsible behaviour, and/or indulgence. ${ }^{[32,33]}$ Therefore, people should act responsibly and be restrained and self-controlled to be well, happy and whole. The implicit assumption of this perspective would be that a man or woman who lives a morally impeccable life will be healthy, whole and complete (as long as they are secured from ill-fate). ${ }^{[34]}$ Upcoming health problems, therefore, should be defied by behaving even more responsibly, restrained and self-controlled.

Applied to health and illness, two main features stand out. First, illnesses are caused by all kinds of external factors, only to be influenced by sensible, responsible behaviour. ${ }^{[32]}$ Secondly, wallowing in physical and mental suffering does not suit the self-controlled person. Only the ultimate aim is important, i.e. health, wellbeing, wholesomeness, purity and harmony. Moral judgement by the health practitioner is the habitual undertone in such interactions with patients. ${ }^{[35,36]}$ For example, blaming the patient for being obese, stigmatisation by healthcare workers for being HIV-infected, or being reluctant to treat a patient who smokes or drinks, fits into the moralist worldview. ${ }^{[35]}$ Accordingly, the student's description of the patient will include a moral undertone. One student reported:

'This [hypertension] is the most prevalent disease that we observed in our community and we have devised a list of possible psychosocial determinants for the prevalence of this disease. The inhabitants live mostly sedentary lifestyles, which are coupled with unhealthy diets consisting of excessive salt, fats and sugar products, a lack of exercise and the normal stresses of life that all serve to exacerbate the progression of the disease. Lack of education serves as a very important factor, as most of the inhabitants have a lack of knowledge when it comes to such diseases, what causes them, and how to reduce their effects once diagnosed. Most of the adults chalk it down to old age when they start getting symptoms of hypertension, and thus get diagnosed in the later stages of the disease, and even then, they underestimate its effects and fail to follow most of the doctor's/healthcarer's professional advice.'

Another student reported:

'X has issues coping with his condition. He now has behavioural problems and that has led to him smoking and being a very violent individual. $\mathrm{He}$ has coping issues and believes that someone might be responsible for his condition? 
In the combination of the positivist and moralist perspectives, a student reported on the effect that being hospitalised had on the patient's understanding of the need for lifestyle changes:

'Ma X initially did not think much of her diagnosis - nor did the family, until she ended up in hospital for a few days. Only then did she see the importance of changing her lifestyle and ... appreciating the extent and seriousness; the outcome has been favourable thus far. When she started feeling sick prior to her diagnosis, she went to an inyanga (Zulu herbalist), who told her she had been bewitched by one of her husband's many mistresses. She believed this and was given herbs that did not help?

\section{A student described:}

'For more than 30 years that patient has been having seizures, but she did not seek medical attention until 4 years ago ... She told me that she went to see a traditional healer, who told her that the ancestors were angry and hungry and that's why she had recurrent and progressively worse seizures. She believed him, a ritual was performed, but nothing changed her seizures ... My main task was to educate her ... on the adverse effect of alcohol on seizures, the effect of missing a dose of medication, and discontinuing the drug without the advice of a doctor ... ?

\section{The spiritualist perspective}

In the spiritualist perspective, the human being is seen as a permanent traveller, usually with a religious belief. ${ }^{[15]}$ Illness is one of the discomforts of travelling that needs to be accepted as is. Accordingly, in the spiritualist view it is not about the disease (positivist perspective), not about the ill person and his narrative (compassionate perspective), and also not about individual efforts needed to become healthy again (moralist perspective). In the spiritualist perspective, man is always en route - his body does not belong to himself. ${ }^{[15]}$ For religious people, praying provides strength to be a righteous person, but for many, even for those in a rapidly secularising world, it is important to note that the view that a person is not in control of his/her own life, is perhaps much more persistent than some might think. ${ }^{[37,38]}$ For many people, their view on health and illness is grounded in their religion. ${ }^{[38]}$ They consider themselves as stewards of their own body, which ultimately belongs to God, nature, or some other physical or non-physical object. As one student described it:

'Mrs D's diseases have impacted her life tremendously. Apart from her physical symptoms, she has had to adjust her daily schedule and activities, which has affected her emotionally. Mrs D copes with the stress and difficulties of her illnesses in a variety of ways. She seeks relief in her hobbies. She finds strength and encouragement in her faith. Lastly, she relies on her husband for support, care, love and assistance. The contributions from each of these aspects of her life allow her to manage her health.'

\section{Another student's view is as follows:}

'Jane has gone from strength to strength and now leads a life that is almost like the one she led before her diagnosis. Her perception on lupus has now changed, as she sees it as one of life's obstacles and something that God has placed in her destiny to make her the person He wants her to be. Her outlook remains positive and she believes that as long as she has faith in God and herself, she can lead a happy life. The main lesson that I took from these visits is that one has to explore to fully grasp the meaning of a disease, and by listening to a patient intently and practising empathy, you are able to heal them not only clinically but psychologically too.'

The following is a student's explanation:

'Mr M understands that he will have to take medication and modify his lifestyle for the rest of his life to achieve optimal control of his blood pressure. Mr M has accepted and is at peace with the present and looks forward to seeing his children achieve independence; then he can die knowing that he has lived a wonderful life.'

In combination with a positivist worldview, one student reported:

'I noted that she still believes that her ancestors are causing her condition ... As a result of her belief she thinks it important that she supplements her western medication provided at the clinic with traditional remedies, such as isinemfu, to achieve optimal control of her condition. She wants to be empowered with knowledge of hypertension ... I advised her to buy an automated blood pressure machine ... and she can check her blood pressure as often as she wants.'

By visiting patients in their home environment, students were able to construct and contextualise their patients' lives more holistically.

A summary and overview of the different perspectives and their key features are presented in Table 1. In most reflections, students expressed combined perspectives, commonly the positivist/biomedical perspective - together with one or more of the others. Overall, however, the positivist perspective was frequently observed in students' reflections. Moralist and spiritualist perspectives were also presented in the data, more often than not combined with one or more of the other perspectives. There was general agreement among the reviewers that students articulated a positivist perspective, clearly ahead of the other three perspectives. As indicated in the abovementioned results, students documented their increased understanding of their patients' circumstances. There was also evidence of their compassion and respect for their patients and their diseases.

\section{Discussion and conclusions}

To explore medical students' learning about health and illness in the community, the analysis in this article was guided by the question of which perspectives undergraduate medical students used in their observations and reports of patients in authentic local contexts. Students conducted their Selective Programmes in their home settings, and were often faced with the reality of living conditions in disadvantaged circumstances. We discuss our findings with regard to two topics: (i) credibility of the four perspectives; and (ii) students' perspectives relating to authentic learning.

\section{Credibility of the four perspectives}

Students at the Nelson R Mandela School of Medicine, Durban, SA, come from a wide range of educational, geographical, cultural and religious backgrounds. We do not pretend that the four perspectives are the only possible ones to classify students' perspectives in a meaningful way. For transparency and dependability, it was significant, however, to see how well the perspectives, constructed in a different society and different time frame, were represented by the four different categories, relating to how current SA medical students regard their patients' illness and disease. In their reflections, many students documented their own shift in greater 
Table 1. Student perspectives on the meaning of disease and illness

\begin{tabular}{|c|c|c|c|c|}
\hline Perspectives & Positivist & Compassionate & Moralist & Spiritualist \\
\hline Key viewpoint & Objective reality & Subjective reality & Social reality & Supernatural reality \\
\hline Key interest & $\begin{array}{l}\text { Focus on clinical features of } \\
\text { the patient }\end{array}$ & $\begin{array}{l}\text { Emphasis on narrative and } \\
\text { experiences of the patient }\end{array}$ & $\begin{array}{l}\text { Description from the perspective } \\
\text { of the professional worker/healer } \\
\text { Moralist undertone }\end{array}$ & $\begin{array}{l}\text { Emphasis on disease and } \\
\text { distress as facts of life } \\
\text { Description of acceptance of } \\
\text { disease and/or resignation by } \\
\text { the patient }\end{array}$ \\
\hline $\begin{array}{l}\text { Student's } \\
\text { identification }\end{array}$ & $\begin{array}{l}\text { Difficulties identifying oneself with } \\
\text { the patient }\end{array}$ & $\begin{array}{l}\text { Strong identification with } \\
\text { the patient }\end{array}$ & $\begin{array}{l}\text { Identification with the patient } \\
\text { to some extent }\end{array}$ & $\begin{array}{l}\text { Identification with the patient } \\
\text { - to some extent }\end{array}$ \\
\hline Distance & $\begin{array}{l}\text { Student keeps distance, consciously } \\
\text { or unconsciously } \\
\text { Detached concern; the encounter } \\
\text { is ritual/clinical }\end{array}$ & Distance nearly absent & $\begin{array}{l}\text { Distance is consciously } \\
\text { maintained (neutral); the } \\
\text { encounter is mainly ritual }\end{array}$ & Some distance is maintained \\
\hline $\begin{array}{l}\text { Ideal patient } \\
\text { outcome }\end{array}$ & $\begin{array}{l}\text { Curing } \\
\text { Stable situation; alleviation from } \\
\text { suffering }\end{array}$ & $\begin{array}{l}\text { Being; alleviation from } \\
\text { suffering }\end{array}$ & Becoming & A meaningful life \\
\hline
\end{tabular}

understanding of their patients' circumstances, and their compassion and respect for many of their patients for the manner in which the latter handled their chronic diseases. Seeing the reality of a patient in their household circumstances is different from seeing a patient in a clinic or hospital, which may be the reason for the increased compassion.

The four perspectives were not mutually exclusive. We found many combinations, in particular a combination of the positivist and compassionate perspectives. This is an important finding, as it is what we usually prefer to see in our (future) doctors - a healthy balance between objective, clinical observation and compassion, and being emotionally restrained and neutral, but certainly not cold and distant. ${ }^{[39]}$

Also interesting was that some of the students expressed a moralist and positivist view regarding their patients. The moralist perspective has always been a fertile ground for the development of disciplines such as public health, social medicine and health promotion. These disciplines exist by virtue of the contrasting merits of people being imprudent $\mathrm{v}$. wise, indulgent v. sober, and responsible v. irresponsible. At the individual level, however, moral judgements may compromise trust relationships. ${ }^{[40,41]}$ In the light of all the evidence that unhealthy lifestyles contribute to many diseases, the pairing of a positivist and moralist worldview, and how this may affect the doctor-patient interaction, is interesting to explore further.

The patients' religious beliefs were another important component of students' views and, interestingly, many of them identified with some of the patients' belief systems. Because students were from the same cultural background as their patients, they were often able to communicate well with them and to use their own access to local information for the benefit of their patients. It is important to note that during data analysis we were not aware of any medical students who considered attendance at traditional healers to be beneficial. However, this conclusion could be influenced by the medical school's strong positivist, biomedical approach, leading to socially desirable answers. It would be another interesting topic to develop further.

\section{Students' perspectives relating to authentic learning}

Students focused on the patient's clinical features. Many students appeared to be keeping their distance, relating a detached concern. Interestingly, students related to the compassionate perspective, as they combined this approach, a development in authentic learning that suggests their potential as future health practitioners identifying with their patients. With the current call for more compassion in healthcare, this is an important finding, and future longitudinal research should build on this. ${ }^{[9]}$

From the viewpoint of experiential learning, the benefits that they experienced through community exposure by visiting patients in their home environments, offered an opportunity to construct and contextualise the patients' lives more holistically. By visiting the same patient during 2 consecutive years, they were also able to gain a better understanding of how the patient was coping with chronic disease/s. Although the analysis provided sufficient applicability and credibility of the four perspectives, evidently the positivist perspective was the most common and easiest to recognise in students, followed by the compassionate perspective. However, the moralist and spiritualist perspectives were helpful additions to these common ones, as we know little about these and how they affect experiential learning regarding the doctor-patient relationship. Further exploration and fine-tuning would be needed for students to gain the maximum benefits of this experience of their AEEs.

\section{Study limitations}

Firstly, students evaluated the data or information presented to them, whether the information was directly observed or told through the eyes of the patient, while the data could be rooted on, e.g. the symptomatology of the body, the clinical history of the patient, or the social and cultural beliefs of the patient. Their experiences therefore remained at the descriptive level, even when they seemed to express an open-mindedness about patients' situations and explanations. In the light of this, although at times we struggled to distinguish between students' and patients' perspectives on the meaning of disease, our data definitely point to experiential learning; Nussbaum ${ }^{[42]}$ describes this as the 'narrative imagination': 'The ability to think what it might be like to be in the shoes of a person different from oneself, to be an intelligent reader of that person's story, and to understand the emotions and wishes and desires that someone so placed might have.'

Secondly, the analyses were done with data collected at one point in time. Therefore, we were not able to unambiguously assess the students' change in perspectives and meaning-giving through the years, except when reported 
retrospectively by the students in their reflections. Only longitudinal data can reveal whether or not the positivist view is tempered by a deeper understanding of the experiences of the patient. However, if through their AEEs with patients in the community, the students have grown in their narrative imagination, then this would be an additional promising outcome of the programme.

Thirdly, as mentioned in the discussion, initially the four perspectives were constructs of a particular society. This viewpoint may question their universal value. Adding to their credibility, our findings proved to be consistent in relation to the context in which they were generated (dependability). Therefore, we continuously analysed and re-examined the data to test whether the four perspectives would hold, which proved to be the case. Related to that, a limitation of our methodological approach in using a directed qualitative content analysis was that it might be less open to generating (new) categories or themes on the meaning of disease in an inductive way, a concern to researchers who believe that qualitative data should only be analysed in such a way. While we are aware of this critique, we discovered that starting from a theoretical framework and then testing whether a limited number of assumptions fit the data, challenged us to discuss our theoretical assumptions and, as mentioned, also might have protected us better against the critique of naive inductivism. In this process, we also searched for evidence that could challenge our perspectives and findings, and documented the steps taken in the entire procedure.

Fourthly, assignments were not written voluntarily and might have been susceptible to social desirability and bias. However, we believe we could avoid this possible bias in our data analysis by focusing not only on 'what' students reported, but also on 'how' they did this. For example, on the 'what', there were clear differences in content, some of them extensively describing 'disease' characteristics, others focusing more on the illness experience and/ or the social consequences (sickness).

Further research to test and substantiate our categories and the longitudinal impact of our findings will, however, be required.

\section{Declaration. None.}

Acknowledgements. None.

Author contributions. FCJS developed the research question, SK was responsible for data collection, and all authors participated in data analysis and writing of the manuscript.

Funding. None.

Conflicts of interest. None.

1. Littlewood S, Ypinazar V, Margolis SA, Scherpbier A, Spencer J, Dornan T. Early practical experience an the social responsiveness of clinical education: Systematic review. BMJ 2005;331(7513):387-391. https://doi org/10.1136/bmj. 331.7513 .387

2. Yardley S, Brosnan C, Richardson J, Hays R. Authentic early experience in medical education: A socio-cultura analysis identifying important variables in learning interactions within workplaces. Adv Health Sci Educ 2013;18(5):873-891. https://doi.org/10.1007/s10459-012-9428-2
3. Itin CM. Reasserting the philosophy of experiential education as a vehicle for change in the 21 st century J Experient Educ 1999;22(2):91. https://doi.org/10.1177/105382599902200206

4. Kolb DA. Experiental Learning. Englewood Cliffs, NJ: Prentice Hall, 1984

5. Dornan T. Osler, Flexner, apprenticeship and 'the new medical education'. J Roy Soc Med 2005;98(3):91-95 https://doi.org/10.1177/014107680509800302

6. Vieira JE, do Patrocínio Tenório Nunes M, de Arruda Martins M. Directing student response to early patient contact by questionnaire. Med Educ 2003;37(2):119-125. https://doi.org/10.1046/j.1365-2923.2003.01431.x

7. Cashman SB, Seifer SD. Service-learning: An integral part of undergraduate public health. Am J Prevent Med 2008;35(3):273-278. https://doi.org/10.1016/j.amepre.2008.06.012

8. Frenk J, Chen L, Bhutta ZA, et al. Health professionals for a new century: Transforming education to strengthen health systems in an interdependent world. Lancet 2010;376(9756):1923-1958. https://doi.org/10.1016/\$01406736(10)61854-5

9. Gaufberg E, Hodges B. Humanism, compassion and the call to caring. Med Educ 2016;50(3):264-266. https: doi.org/10.1111/medu. 12961

10. Stevens FCJ, van der Vleuten CPM. Medical education. In: Wright JD, ed. International Encyclopedia of the Social and Behavioral Sciences, 15. 2nd ed. Oxford: Elsevier, 2015:81-85.

11. Sulzer SH, Feinstein NW, Wendland CL. Assessing empathy development in medical education: A systematic 1. Sulzer SH, Feinstein NW, Wendland CL. Assessing empathy development
review. Med Educ 2016;50(3):300-310. https://doi.org/10.1111/medu.12806

12. Wear D, Zarconi J. Humanism and other acts of faith. Med Educ 2016;50(3):271-272. https://doi.org/10.1111/
review medu. 12974

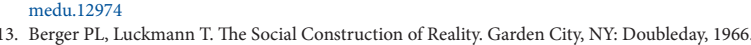

14. Guba EG. The Paradigm Dialog. Thousand Oaks, CA: Sage, 1990.

15. Philipsen H. Gezondheidszorg als Project en Bejegening: Waarden ten Aanzien van Ziekte, Gezondheid en Samenleving. Maastricht: Maastricht University, 1988

16. Bloom SW. Structure and ideology in medical education: An analysis of resistance to change. J Health Soc Behav 1988;29(4):294-306.

17. Bloom SW. The Word as Scalpel: A History of Medical Sociology. Oxford: Oxford University Press, 2002.

18. Kluckhohn FR, Strodtbeck FL. Variations in Value Orientations. Evanston, Ill: Row, Peterson, 1961

19. Engel GL. The need for a new medical model: A challenge for biomedicine. Science 1977;196(4286):129-136

20. Kleinman A. The Illness Narratives: Suffering, Healing, and the Human Condition. New York: Basic Books, 1988

21. Philipsen $\mathrm{H}$, Stevens $\mathrm{FCJ}$. Modernization, rationality and continuity of care: Theoretical concepts and empirical findings. Sociol Focus 1997;30(2):189-204. https://doi.org/10.1080/00380237.1997.10570691

22. Twaddle AC. Sickness and the sickness career: Some implications. In: Eisenberg L, Kleinman A, eds. The Relevance of Social Science for Medicine. Dordrecht: Springer, 1981:111-133.

23. Knight SE, van Wyk JM, Mahomed S. Teaching research: A programme to develop research capacity in undergraduate medical students at the University of KwaZulu-Natal, South Africa. BMC Med Educ 2016;16:61-69. hindergraduate medical students at the Univer

24. Kwizera EN, Iputo JE. Addressing social responsibility in medical education: The African way. Med Teach Kwizera EN, Iputo JE. Addressing social responsibility in medical
2011;33(8):649-653. https://doi.org/10.3109/0142159X.2011.590247

25. Good BJ, Good M-ID. The meaning of symptoms: A cultural hermeneutic model for clinical practice. In:

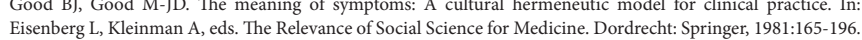
Eisenberg L, Kleinman A, eds. The Relevance of Social Science for Medicine. Dordrecht: Springer, 1981:165-196.
Hsieh H-F, Shannon SE. Three approaches to qualitative content analysis. Qualitat Health Res 2005;15(9):1277-1288 26. Hsieh H-F, Shannon SE. Three approaches to
https://doi.org/10.1177/1049732305276687

27. Silverman D. Doing Qualitative Research: A Practical Handbook. Thousand Oaks, CA: Sage, 2013.

28. Bryman A. Social Research Methods. Oxford: Oxford University Press, 2008.

29. Fox R, Lief H. The Psychological Basis of Medical Practice. New York, NY: Harper and Row, 1963:12-35.

30. Goffman E. On face-work: An analysis of ritual elements in social interaction. Psychiatry 1955;18(3):213-23

31. Goffman E. Interaction Ritual: Essays on Face-to-face Behavior. New York: Doubleday Anchor, 1967.

32. Crawford R. Health as a meaningful social practice. Health 2006;10(4):401-420. https://doi.org/10.1177/1049732305276687

33. Jallinoja P, Absetz P, Kuronen R, et al. The dilemma of patient responsibility for lifestyle change: Perceptions among primary care physicians and nurses. Scand J Primary Health Care 2007;25(4):244-249. https://doi. org/10.1080/02813430701691778

34. Brown RCH. Moral responsibility for (un)healthy behaviour. J Med Ethics 2013;39(11):695-698. https://doi. org/10.1136/medethics-2012-100774

35. Murrell VS. The failure of medical education to develop moral reasoning in medical students. Int J Med Educ 2014;5:219-225. https://doi.org/10.5116/ijme.547c.e2d1

36. Hill TE. How clinicians make (or avoid) moral judgments of patients: Implications of the evidence for relationships . Hill TE. How clinicians make (or avoid) moral judgments of patients: Implications of the evidence for
and research. Philosophy Ethics Human Med 2010;5:11-25. https://doi.org/10.1186/1747-5341-5-11

37. Hill PC, Pargament KI. Advances in the conceptualization and measurement of religion and spirituality: Implications for physical and mental health research. Am Psychol 2003;58(1):64-74. https://doi.org/10.1037/0003-
066X.58.1.64 066X.58.1.6

38. Miller WR, Thoresen CE. Spirituality, religion, and health: An emerging research field. Am Psychol 2003;58(1):24-35 https://doi.org/10.1037/0003-066X.58.1.24

39. Stevens FCJ, Goulbourne J. Cultural competence in medical education. In: Cockerham WC, Dingwall R, Quah SR, eds The Wiley Blackwell Encyclopedia of Health, Illness, Behavior, and Society. Oxford: Wiley Blackwell, 2014:13351339.

0. Cruess RL, Cruess SR. Professional trust. In: Cockerham WC, Dingwall R, Quah SR, eds. The Wiley Blackwel Encyclopedia of Health, Illness, Behavior, and Society. Oxford: Wiley Blackwell, 2014:1900-1902.

41. Mechanic D. In my chosen doctor I trust. BMJ 2004;329(7480):1418-1419. https://doi.org/10.1136/bmj.329.7480 1418

42. Nussbaum MC. Cultivating Humanity. A Classical Defence of Reform in Liberal Education. Cambridge, MA: Harvard University Press, 1998:10-11.

Accepted 11 June 2018 